\title{
NAVIGATED TOTAL KNEE ARTHROPLASTY FOR OSTEOARTHRITIS WITH EXTRA-ARTICULAR DEFORMITY
}

\section{ARTROPLASTA TOTAL DO GENE NAVEGATIVA PARA OSTEOARTRIA COM DEFORMIDADE EXTRA-ARTICULAR}

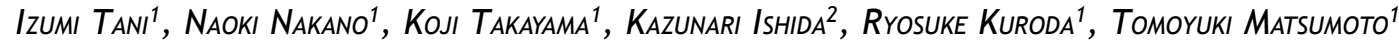 \\ 1. Department of Orthopedic Surgery, Kobe University Graduate School of Medicine, Kobe, Japan. \\ 2. Department of Orthopedic Surgery, Kobe Kaisei Hospital, Kobe, Japan.
}

\section{ABSTRACT}

Objective: It is difficult to achieve proper alignment after total knee arthroplasty (TKA) in patients with extra-articular deformity (EAD) because of altered anatomical axis and distorted landmarks. As of this writing, only case series have been reported with regard to the usefulness of computer-assisted navigation systems for TKA with EAD. This study therefore compared outcomes in TKA with EAD, with and without navigation. Methods: Fourteen osteoarthritis patients with EAD due to previous fracture malunion or operations were assessed. Seven TKAs were performed with navigation (navigation group) and another 7 were performed without navigation (manual group). Clinical and radiographic outcomes were compared before and two years after surgery. Results: The mean postoperative Knee Society function score was significantly higher in the navigation group. No significant difference was found in postoperative range of motion and Knee Society knee score. The rate of outliers in radiographic outcomes tended to be lower in the navigation group. Conclusion: Better clinical outcomes were achieved in cases in which navigation was used. Computer-assisted navigation is useful in TKA for patients with EAD. Level of Evidence III; Case control study.

Keywords: Arthroplasty, replacement, knee. Comparative study.

\section{RESUMO}

Objetivo: para pacientes com deformidade extra-articular (EAD), é difícil alcançar o alinhamento adequado após a artroplastia total do joelho (TKA) por causa de um eixo anatômico alterado e marcos distorcidos. Somente foram relatadas apenas séries de casos quanto à utilidade do sistema de navegação assistido por computador para TKA com a EAD até agora. Neste estudo, tentamos comparar resultados em TKA com EAD com e sem navegação. Métodos: Quatorze pacientes com osteoartrite com EAD devido a maluniões ou operações de fratura anteriores foram avaliadas. 7 TKAs foram realizados com navegação (navegação em grupo) e outros 7 TKAs foram realizados sem ele (manual de grupo). Antes e dpois anos após a cirurgia, os desfechos clínicos e radiográficos foram comparados. Resultados: O resultado médio da função Knee Society pós-operatório foi significativamente maior na navegação do grupo do que no manual do grupo. Não houve diferença significativa na amplitude de movimento pós-operatória e na pontuação do joelho na joia. A taxa de outliers em resultados radiográficos tende a ser menor na navegação do grupo do que no manual do grupo. Conclusão: foram obtidos melhores resultados clínicos na navegação em grupo. O sistema de navegação assistido por computador é útil em TKA para pacientes com EAD. Nível de Evidência III; Estudo de caso-controle.

Descritores: Artroplastia do joelho. Estudo comparativo.

Citation: Tani I, Nakano N, Takayama K, Ishida K, Kuroda R, Matsumoto T. Navigated total knee arthroplasty for osteoarthritis with extra-articular deformity. Acta Ortop Bras. [online]. 2018;26(3):170-4. Available from URL: http://www.scielo.br/aob.

\section{INTRODUCTION}

Total knee arthroplasty (TKA) is a successful surgical procedure for patients with end-stage osteoarthritis (OA). Achievement of proper alignment and appropriate soft tissue balancing is essential for successful clinical outcomes in TKA. Malalignment caused by improper osteotomy and component positioning leads to poor function, early loosening, and high risk of polyethylene wear. ${ }^{1}$ Lonner et al. ${ }^{2}$ reported difficulty in achieving proper alignment after surgery in patients with extra-articular deformity (EAD) because of an altered anatomical axis and distorted landmarks.
Computer-assisted surgery has been used for over 10 years to assist in the placement of cutting guides, instruments, and implants, and was developed to overcome some limitations of standard mechanical instrumentation. ${ }^{3}$ Several comparative studies have revealed that computer-assisted surgery was effective in TKA to reduce mechanical axis outliers after surgery, and this procedure is now used widely. ${ }^{4-7}$ Ishida et al. ${ }^{8}$ reported better objective outcomes from use of a navigation system over conventional procedures, including range of motion (ROM) and radiological assessment at 5 years after TKA. With this system, surgeons can even safely operate

All authors declare no potential conflict of interest related to this article.

Work conducted at the Kobe University Graduate School of Medicine, Kobe, Japan.

Correspondence: Tomoyuki Matsumoto. Department of Orthopedic Surgery, Kobe University Graduate School of Medicine 7-5-1 Kusunoki-cho, Chuo-ku, Kobe 650-0017, japan.matsun@m4.dion.ne.jp 
on patients with severe bone deformity in whom conventional instrumentation cannot be used. Especially for cases with EAD, several surgeons have reported the utility of the navigation system for achieving better clinical and radiographic outcomes. ${ }^{5}$

However, nearly all reports on TKA for patients with EAD to date were case series without controls, which are not sufficient to determine the utility of the navigation system. ${ }^{4-7,9}$ The current study attempts to clarify the utility of the navigation system.

\section{MATERIALS AND METHODS}

\section{Patient characteristics and procedures}

From October 2005 to September 2012, 14 patients (4 men and 10 women) with $\mathrm{OA}$ and $\mathrm{EAD}$ caused by either femoral or tibial trauma or previous leg surgery underwent TKAs at our institution. The study was approved by the institutional review boards of the participating hospitals, and all participants signed the free and informed consent term. The protocol of this study was approved by the Ethics Committee for Human and Animal Research of Graduate School of Medicine Kobe University (Protocol number: 1510). Inclusion criteria were the presence of extra-articular coronal deformity $>3^{\circ}$ in the femur or tibia. Patients with deformities $<3^{\circ}$ were excluded. Patient demographic data are shown in Table 1. There were 11 patients with tibial deformities, and the remaining 3 patients had femoral deformities. They were all diagnosed with $\mathrm{OA}$, not with rheumatoid arthritis. Previous fracture malunion caused 4 of the deformities, and the others were caused by previous surgeries such as high tibial osteotomy, Schanz osteotomy, or femoral varus osteotomy. Of these cases, TKAs for 7 patients were performed with computer-assisted navigation systems (navigation group) and TKAs for the other 7 patients were performed without a computer-assisted navigation system (manual group). In the navigation group, 3 patients had an average femoral deformity of $15.1^{\circ}$ (range: $28.2^{\circ}$ in valgus to $14.5^{\circ}$ in varus) and 4 patients had an average tibial deformity of $7.3^{\circ}$ (range: $3^{\circ}$ in valgus to $12^{\circ}$ in varus) in the coronal plane. In the manual group, all patients had tibial deformities, and the average degree of deformity was $9.3^{\circ}$ (range, $18^{\circ}$ in valgus to $19.4^{\circ}$ in varus) in the coronal plane.

All surgeries were performed by two senior authors (TM and $\mathrm{KI}$ ), and six different types of prostheses were implanted (Zimmer NexGen LPS-Flex in 6 knees, B. Braun Aesculap e-motion in 4 knees, Depuy $\mathrm{RP}-\mathrm{F}$ in 3 knees, and Stryker Triathlon in 1 knee). Posterior-stabilized (PS) prostheses were used in 8 knees and cruciate-retaining (CR) prostheses were used in 6 knees.

\section{Operative Technique}

In the navigation group, the prostheses were implanted with the aid of a CT-free navigation system (Depuy-Brain LAB, Heimstetten, Germany or B. Braun Aesculap, Tuttlingen, Germany). To define the mechanical axis of the tibia, the center of the tibial plateau was identified simply using the tip of the pointer. The anteroposterior direction of the tibia was subsequently defined in the same way after defining the medial and lateral articular surfaces and the anterior contour. Femoral registration consisted of identifying the medial and lateral epicondyles, the articular surface of the medial and lateral

Table 1. Demographic data of for navigation and manual groups.

\begin{tabular}{c|c|c}
\hline \multirow{2}{*}{ Characteristics } & \multicolumn{2}{|c}{ Group } \\
\cline { 2 - 3 } & navigation & manual \\
\hline Sex (male/female (\% male)) & $1 / 6(14.3 \%)$ & $3 / 4(42.9 \%)$ \\
\hline BMI (kg/m (mean SD)) & 25.54 .4 & 27.74 .6 \\
\hline Age at time of TKA (years (mean SD)) & 75.04 .2 & 72.06 .0 \\
\hline
\end{tabular}

BMI, body mass index; TKA, total knee arthroplasty; SD, standard deviation. condyles, and the anterior sulcus. To define the mechanical axis of the femur, the deepest point of the intercondylar notch was identified simply using the tip of the pointer. The proximal tibial osteotomy was performed with $3^{\circ}$ posterior inclination in the sagittal plane. Once the final components were in place, soft tissue balancing was performed to achieve proper collateral ligament tension following the indications of the navigation system.

In the manual group, we used a measured resection technique. The angular deformity and the mechanical axis of the femur were determined by preoperative, weight-bearing, full-length radiographs. The intra-articular resection of the distal femoral bone was made at a $90^{\circ}$ angle relative to the mechanical axis.

For the tibial bony cut, an intramedullary rod was used for most cases, while an extra-medullary guiding rod was used in some cases with severe tibial angular deformities. The rotational alignment of the femoral prosthesis was set at $3^{\circ}$ of external rotation in relation to the posterior condylar axis, and anterior and posterior femoral bony resections were performed with posterior referencing. The proximal tibial osteotomy was performed perpendicular to the long axis in the coronal plane. For the sagittal plane of the tibia, $3^{\circ}$ of posterior inclination in PS-TKA and $7^{\circ}$ of posterior inclination in CR-TKA were targeted.

\section{Clinical and Radiological Measurements}

Before and 2 years after surgery, clinical and radiological evaluations were performed in both groups. To assess clinical outcomes, the maximum knee extension and flexion angle, Knee Society knee score (KSKS), and Knee Society function score (KSFS) were evaluated. ${ }^{10}$ To assess radiological outcomes, the Hip-Knee-Ankle (HKA) angle was measured before and 2 years after the operation in weight-bearing radiographs (a 320mA, 0.03-s exposure at 80-100kV, depending on soft tissue thickness). Component angles, including the femoral component angle in the coronal plane (cFCA), tibial component angle in the coronal plane (CTCA), femoral component angle in the sagittal plane (SFCA) and tibial component angle in the sagittal plane (sTCA), were measured to assess the accuracy in implantation of the prostheses 2 years after surgery (Figure 1) In addition, the ratio

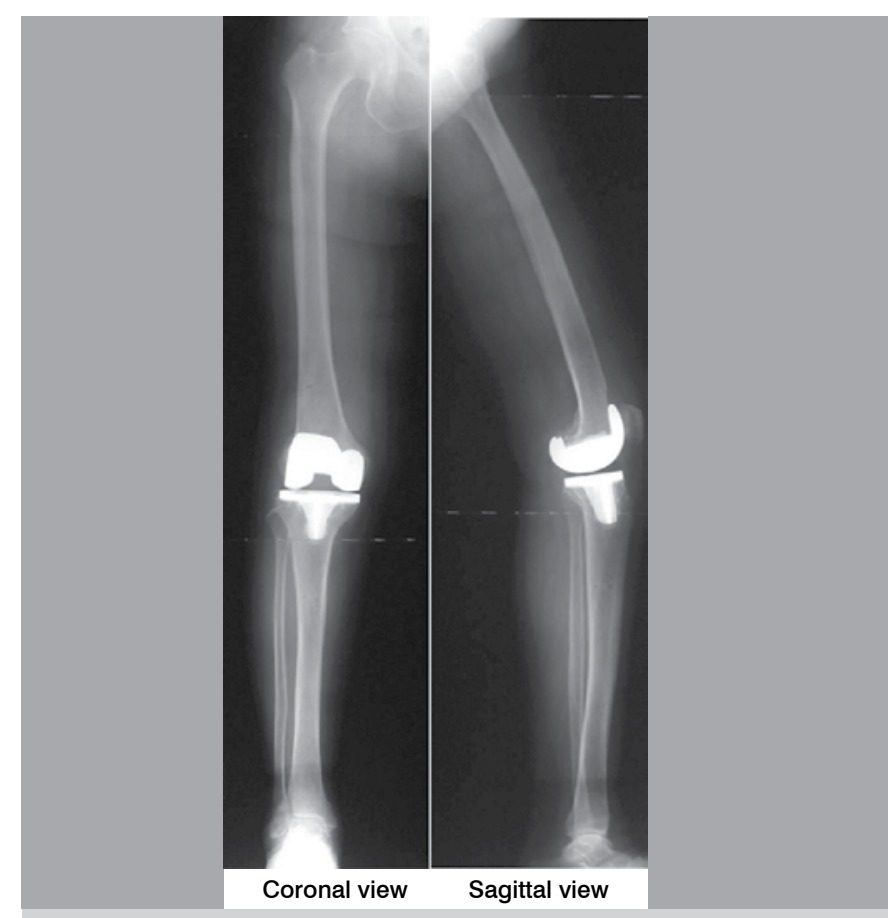

Figure 1. Postoperative X-ray 
of patients with proper alignment in each. radiological assessment category (HKA angle, 180 $\pm 3^{\circ}$; cFCA, 90 $\pm 2^{\circ}$; cTCA, 90 $\pm 2^{\circ}$; sFCA, $87 \pm 2^{\circ}$; sTCA for the navigation group and PS-TKA in the manual group, $87 \pm 2^{\circ}$ and sTCA for CR-TKA in the manual group, $83 \pm 2^{\circ}$ ) were compared between the groups. All radiological measurements were performed by three independent observers. Intra- and inter-observer reliability was almost perfect for both groups.

\section{Statistical analyses}

All statistical analyses were performed using Microsoft Excel (Microsoft Japan Inc. Tokyo, Japan). The differences in the 2 groups were analyzed using a chi-square test and a non-paired, two-tailed Student's t-test, which assumed equal dispersion. $P<0.05$ indicated statistical significance.

\section{RESULTS}

The clinical results are shown in Table 2. The extremes of ROM improved on average from $-5.7-107.9^{\circ}$ to $-2.9-127.1^{\circ}$ in the navigation group, whereas it improved from $-8.8-100.0^{\circ}$ pre-operatively to $-0.8-115.7^{\circ}$ post-operatively in the manual group. KSKS improved from $58.9 \pm 9.2$ points before surgery to $93.3 \pm 6.9$ points at the last follow-up in the navigation group, while it improved from $47.0 \pm 18.4$ points to $93.7 \pm 4.1$ points in the manual group. There were no significant differences between two groups in ROM and KSKS. KSFS improved from $56.6 \pm 10.8$ points before surgery to $93.3 \pm 5.9$ points at the last follow-up in the navigation group, while it improved from $49.7 \pm 27.8$ points to $73.6 \pm 15.4$ points in the manual group. Postoperative KSFS in the navigation group was significantly better than in the manual group.

The radiological results are shown in Table 2 and 3. HKA angle improved from $10.6^{\circ}$ pre-operatively to $0.3^{\circ}$ post-operatively in the navigation group, while it improved from $9.3^{\circ}$ to $0.7^{\circ}$ in the manual group. No significant difference was shown in the rate of patients with outliers in HKA angle between 2 groups. (Table 2 and Figure 2) At 2 years post-procedure in the navigation group, the average values for CFCA, cTCA, sFCA and sTCA were $90.6^{\circ}, 89.8^{\circ}, 87.5^{\circ}$ and $85.1^{\circ}$, respectively. In the manual group, the average values for cFCA, cTCA, sFCA and sTCA were $92.0^{\circ}, 88.2^{\circ}, 85.4^{\circ}$ and $84.2^{\circ}$,

Table 2. Clinical results and radiological results for Hip-Knee-Ankle angle in navigation and manual groups.

\begin{tabular}{|c|c|c|c|c|}
\hline \multirow{2}{*}{\multicolumn{2}{|c|}{ Characteristics }} & \multicolumn{2}{|c|}{ Group } & \multirow{3}{*}{\begin{tabular}{|c|} 
P value \\
0.20
\end{tabular}} \\
\hline & & \multirow{2}{*}{$\begin{array}{l}\text { Navigation } \\
-5.7(-10-0)\end{array}$} & \multirow{2}{*}{$\frac{\text { Manual }}{-8.8(-30-0)}$} & \\
\hline Maximum extension angle & Preop & & & \\
\hline (degrees (mean (range))) & Postop & $-2.9(-5-0)$ & $-0.8(-10-0)$ & 0.70 \\
\hline \multirow{2}{*}{$\begin{array}{l}\text { Maximum flexion angle } \\
\text { (degrees (mean (range))) }\end{array}$} & Preop & $107.9(90-125)$ & $100.0(90-120)$ & 0.30 \\
\hline & Postop & $127.1(110-140)$ & $115.7(90-135)$ & 0.15 \\
\hline \multirow{2}{*}{ KSKS (mean SE) } & Preop & $58.9 \pm 9.2$ & $47.0 \pm 18.4$ & 0.15 \\
\hline & Postop & $93.3 \pm 6.9$ & $93.7 \pm 4.1$ & 0.89 \\
\hline \multirow{2}{*}{ KSFS (mean SE) } & Preop & $56.6 \pm 10.8$ & $49.7 \pm 27.8$ & 0.55 \\
\hline & Postop & $93.3 \pm 5.9$ & $73.6 \pm 15.4$ & $0.008^{\star}$ \\
\hline \multirow{2}{*}{$\begin{array}{c}\text { HKA angle } \\
\text { (degrees (mean SE)) }\end{array}$} & Preop & $10.6 \pm 8.9$ in varus & $9.3 \pm 6.7$ in varus & 0.76 \\
\hline & Postop & $0.3 \pm 2.3$ in varus & $0.7 \pm 4.1$ in valgus & 0.31 \\
\hline \multirow{2}{*}{$\begin{array}{l}\text { Rate of patients with outliers } \\
\text { (\% (patients with outlier/ } \\
\text { all patients)) }\end{array}$} & Preop & $71.4(5 / 7)$ & $85.7(6 / 7)$ & 0.51 \\
\hline & Postop & $0.0(0 / 7)$ & $28.6(2 / 7)$ & 0.13 \\
\hline
\end{tabular}

respectively. There was no significant difference between the two groups for each component angle. (Table 3) The rates of patients with outliers in each component angle were: cFCA, $14.3 \%$ in the navigation group and $28.6 \%$ in the manual group; cTCA, $0.0 \%$ in the navigation group and $28.6 \%$ in the manual group; sFCA, $14.3 \%$ in the navigation group and $42.9 \%$ in the manual group; sTCA, $14.3 \%$ in the navigation group and $42.9 \%$ in the manual group. There was no significant difference between the two groups in the rate of patients with outliers in each component angle, although the rate of outliers in the navigation group tended to be lower than in the manual group. (Table 3 and Figures 3,4 )

There were no complications related to the use of the computer-assisted navigation system in the navigation group (such as pin-site infection or fracture).

Table 3. Radiological results for each component angle and rate of patients with outliers in each component angle in navigation and manual groups.

\begin{tabular}{c|c|c|c|c}
\hline \multirow{2}{*}{} & \multicolumn{2}{|c|}{ Group } & \multirow{2}{*}{ P value } \\
\cline { 2 - 4 } & Navigation & Manual & \\
\hline \multicolumn{2}{c|}{ cFCA (degrees) } & $90.6 \pm 1.4$ & $92.0 \pm 2.3$ & 0.20 \\
\hline \multicolumn{2}{c|}{ cTCA (degrees) } & $89.8 \pm 1.5$ & $88.2 \pm 2.9$ & 0.22 \\
\hline \multicolumn{2}{c|}{ sFCA (degrees) } & $87.5 \pm 1.9$ & $85.4 \pm 3.9$ & 0.21 \\
\hline \multicolumn{2}{c|}{ sTCA (degrees) } & $85.1 \pm 1.8$ & $84.2 \pm 1.8$ & 0.37 \\
\hline \multirow{2}{*}{$\begin{array}{c}\text { Rate of patients } \\
\text { with outlier } \\
(\% \text { (patients with } \\
\text { outlier/all patients)) }\end{array}$} & cFCA & $14.3(1 / 7)$ & $28.6(2 / 7)$ & 0.51 \\
\cline { 2 - 4 } & CTCA & $0.0(0 / 7)$ & $28.6(2 / 7)$ & 0.12 \\
\cline { 2 - 4 } & sFCA & $14.3(1 / 7)$ & $42.9(3 / 7)$ & 0.24 \\
\hline
\end{tabular}

Definition of outlier in each component angle: cFCA, $90 \pm 2^{\circ}$; cTCA, $90 \pm 2^{\circ}$; sFCA, $87 \pm 2^{\circ}$; sTCA $83 \pm 2^{\circ}$ (CR-TKA in manual group) or $87 \pm 2^{\circ}$ (Navigation group and PS-TKA in manual group). Al radiological data were shown as mean \pm SE. Abbreviations: CFCA, femoral component angle in the coronal plane; cTCA, tibial component angle in the coronal plane; sFCA, femoral component angle in the sagittal plane; STCA, tibial component angle in the sagittal plane; TKA, total knee arthroplasty; $\mathrm{CR}$, cruciate-retaining; PS, posterior-stabilized. $\mathrm{P}<0.05$ was considered statistically significant.

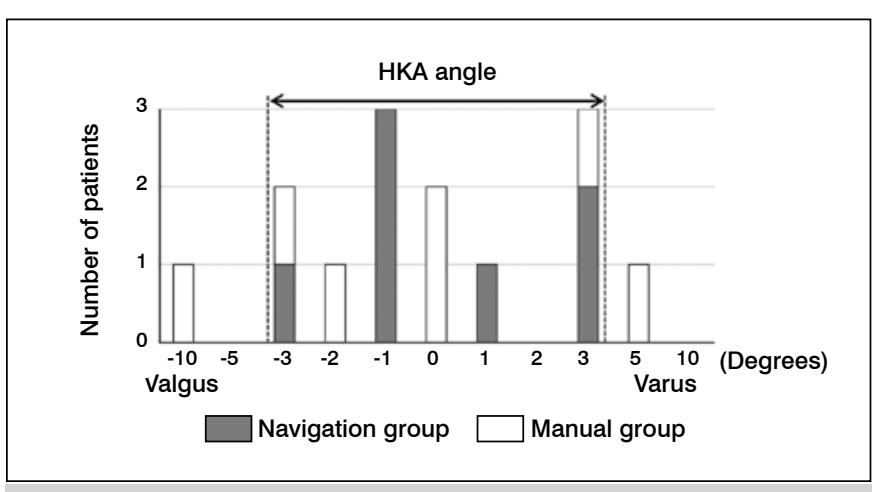

Figure 2. Hip-Knee-Ankle (HKA) angle for each group.

\section{DISCUSSION}

This comparative study attempted to estimate the effectiveness of navigation systems in TKA with EAD. The most important finding was that using navigation systems in TKA with EAD was somewhat beneficial for achieving better clinical results (KSFS), while using the systems showed no significant positive effect in other clinical results and radiological results.

Although there are still arguments about alignment accuracy, additional operative time and cost efficiency, ${ }^{2,3}$ the benefits of using navigation systems in routine TKA have recently been reported by many researchers. ${ }^{11-14}$ Though some authors reported good clinical and radiological outcomes of TKA in EAD using navigation 


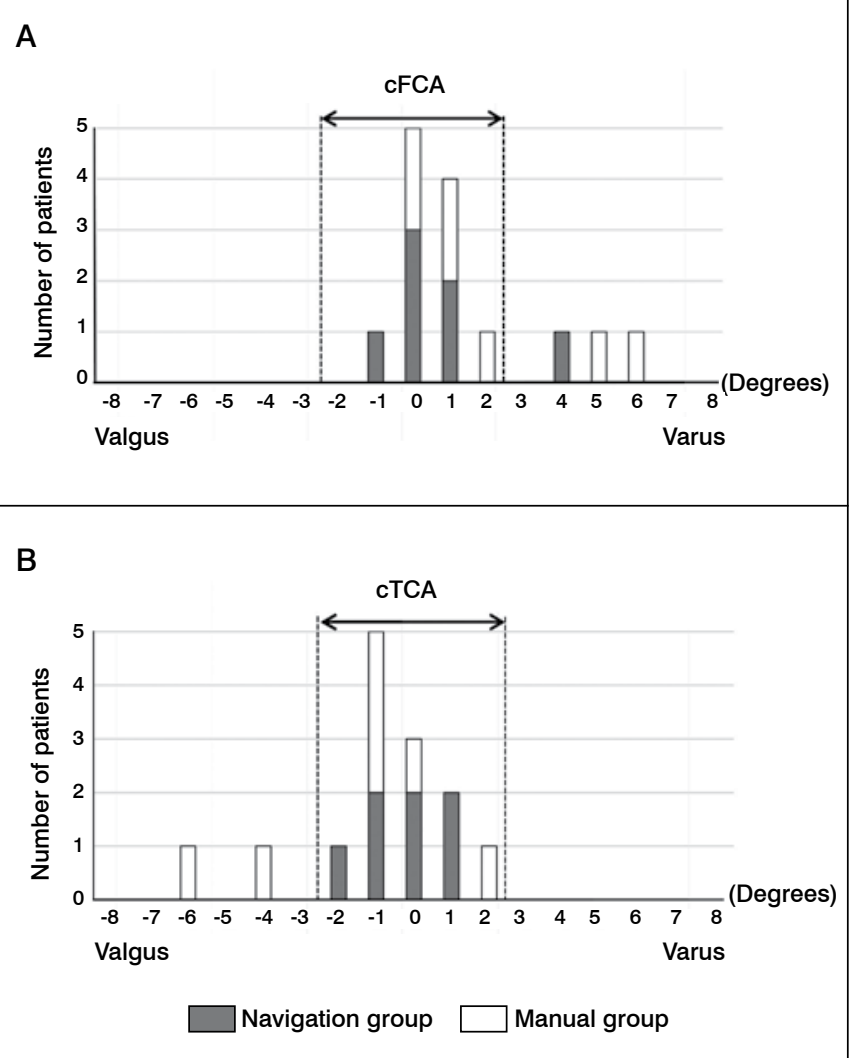

Figure 3. Femoral component angle in the coronal plane (cFCA) and tibial component angle (CTCA) in the coronal plane of each group.

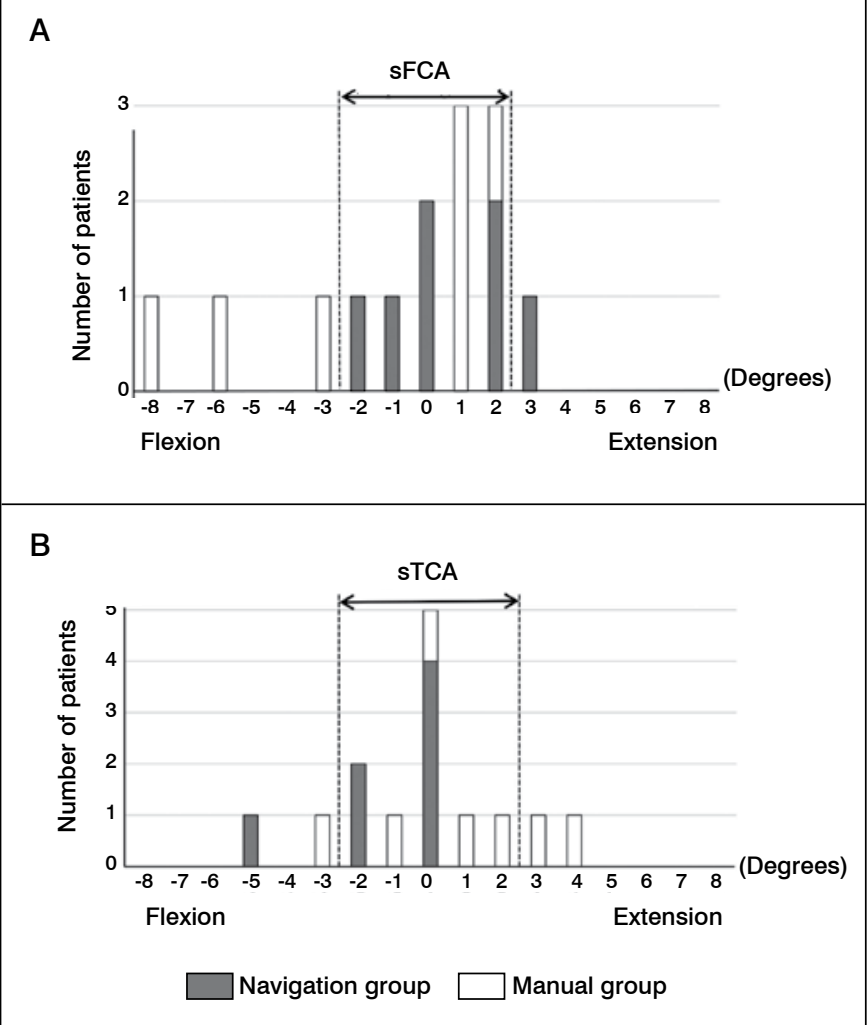

Figure 4. Femoral component angle in the sagittal plane (SFCA) and tibial component angle (sTCA) in the sagittal plane for each group. systems, ${ }^{4-7,7,15}$ the number of patients in these reports were small and there has been no comparative study with the conventional technique. Klein et al. ${ }^{6}$ described a case series comprising 5 patients who underwent TKA with navigation systems, and reported good postoperative radiological outcomes including the mechanical axis of the lower extremity. Fehring et al. ${ }^{4}$ described the use of navigation systems for TKA in patients with EAD and reported acceptable postoperative mechanical axis in 9 of the 10 cases. Additionally, Bottros et al. ${ }^{5}$ described the use of navigation systems for TKA in 7 patients (9 knees) with EAD, and reported the effectiveness of navigation systems. Conventional mechanical alignment guides for TKA restored the mechanical axis using anatomical femoral and tibial shape. On the other hand, navigation systems can establish the mechanical axis regardless of the shape of the femoral and tibial shaft. From this point of view, using navigation systems could be beneficial in TKA with EAD to recreate the correct mechanical axis when femoral or tibial deformities are present. Furthermore, in cases of TKA with retained previous hardware or bony sclerosis from previous surgery, surgeons could consider navigation systems, since it may be difficult to use standard surgical instrumentation such as intramedullary rods. In addition, using navigation systems may reduce blood loss and potential risk from intramedullary rods. ${ }^{13}$ We assume that a slightly better knee flexion angle in the navigation group (125.7 $7^{\circ}$ in the navigation group vs. $115.7^{\circ}$ in the manual group) is part of the reason for better postoperative KSFS outcomes achieved in the navigation group, although the results were not statistically significant $(P=0.15)$. Increased knee flexion may lead to better KSFS as deep knee flexion is needed to climb/descend stairs, which is one of the components of the KSFS. Devers et al. ${ }^{16}$ stated that increased knee flexion after TKA may lead to restoration of normal knee function and improved functional ability such as stair-climbing. Furthermore, Ritter et al. ${ }^{17}$ found that increased knee flexion was associated with better outcomes for stair-climbing. Finally, Meneghini et al. ${ }^{18}$ showed that knee flexion $>125^{\circ}$ was beneficial for stair-climbing. These studies could support our current results. In our study, the rate of radiological outliers in all component angles tended to be slightly lower in the navigation group than the manual group, although no significant difference could be found between the groups because the sample size was so small. As for coronal alignments, previous studies showed that using navigation systems could contribute to fewer outliers in coronal alignment, ${ }^{14}$ and these studies are consistent with our current results. With regard to sagittal alignment, Matsumoto et al. ${ }^{19}$ described desirable sagittal femoral component implantation leading to favorable physiological joint condition and better postoperative ROM in TKA, which could also support our results. This study has several limitations. First, the population size (14 patients) was small. Larger-scale studies are needed to prove our current results. We should have investigated with more than 64 patients in each group (with power $=0.8, \square=0.5$ ). Second, the follow-up period (2 years) was relatively short; a longer follow-up is necessary to verify the results. Third, the operations were not performed by a single surgeon, although the technique was well-standardized among all the surgeons. Finally, we did not record any patient-derived outcome scores such as the Knee Society's new scoring system, KSS 2011. ${ }^{20}$

\section{CONCLUSION}

In cases of TKA with EAD, better postoperative KSFS was achieved in the navigation group compared to the manual group, while no significant differences in other clinical outcomes were found. No significant differences in radiological outcomes were found between the groups, though fewer radiological outliers were found in the navigation group than the manual group. Further advanced, large-scale studies with longer follow-up are necessary to verify our results. 
AUTHORS' CONTRIBUTIONS: Each author made significant individual contributions to this manuscript. IT (0000-0002-9711-7322)*: wrote and reviewed the article; TM (0000-0003-4587-0029)* and NN (0000-0003-4067-9233)*: performed the surgeries, analyzed the data, and wrote the article; KI (0000-0001-7211-7011)* and KT (0000-0001-9449-0474)*: drafted and reviewed the article and contributed to the intellectual concept of the study; RK $(0000-0001-5097-7264)^{*}$ :and all authors contributed to the intellectual concept of the study and approved the final version of the manuscript. *ORCID (Open Researcher and Contributor ID).

\section{REFERENCES}

1. Berger RA, Rubash HE, Seel MJ, Thompson WH, Crossett LS. Determining the rotational alignment of the femoral component in total knee arthroplasty using the epicondylar axis. Clin Orthop Relat Res. 1993;(286):40-47.

2. Lonner JH, Siliski JM, Lotke PA. Simultaneous femoral osteotomy and total knee arthroplasty for treatment of osteoarthritis associated with severe extra-articular deformity. J Bone Joint Surg Am. 2000;82(3):342-48.

3. Cameron HU, Welsh RP. Potential complications of total knee replacement following tibial osteotomy. Orthop Rev. 1988;17(1):39-43.

4. Fehring TK, Mason JB, Moskal J, Pollock DC, Mann J, Williams VJ. When computer-assisted knee replacement is the best alternative. Clin Orthop Relat Res. 2006;452:132-6.

5. Bottros J, Klika AK, Lee HH, Polousky J, Barsoum WK. The use of navigation in total knee arthroplasty for patients with extra-articular deformity. J Arthroplasty. 2008;23(1):74-8.

6. Klein GR, Austin MS, Smith EB, Hozack WJ. Total knee arthroplasty using computer-assisted navigation in patients with deformities of the femur and tibia. J Arthroplasty. 2006;21(2):284-8.

7. Chou WY, Ko JY, Wang CJ, Wang FS, Wu RW, Wong T. Navigation-assisted total knee arthroplasty for a knee with malunion of the distal femur. J Arthroplasty. 2008;23(8):1213-39.

8. Ishida K, Matsumoto T, Tsumura N, Kubo S, Kitagawa A, Chin T et al. Mid-term outcomes of computer-assisted total knee arthroplasty. Knee Surg Sports Traumatol Arthrosc. 2011;19(7):1107-12.

9. Kim KI, Ramteke AA, Bae DK. Navigation-assisted minimal invasive total knee arthroplasty in patients with extra-articular femoral deformity. J Arthroplasty. 2010;25(4):e617-22.

10. Insall JN, Dorr LD, Scott RD, Scott WN. Rationale of the Knee Society clinical rating system. Clin Orthop Relat Res. 1989;(248):13-4.
11. Ensini A, Catani F, Leardini A, Romagnoli M, Giannini S. Alignments and clinical results in conventional and navigated total knee arthroplasty. Clin Orthop Relat Res. 2007;457:156-62.

12. Bathis H, Perlick L, Tingart M, Luring C, Zurakowski D, Grifka J. Alignment in total knee arthroplasty. A comparison of computer-assisted surgery with the conventional technique. J Bone Joint Surg Br. 2004;86(5):682-7.

13. Bolognesi $M$, Hofmann A. Computer navigation versus standard instrumentation for TKA: a single-surgeon experience. Clin Orthop Relat Res. 2005;440:162-9.

14. Chauhan SK, Scott RG, BreidahI W, Beaver RJ. Computer-assisted knee arthroplasty versus a conventional jig-based technique. A randomised, prospective trial. J Bone Joint Surg Br. 2004;86(3):372-7.

15. Mullaji A, Shetty GM. Computer-assisted total knee arthroplasty for arthritis with extra-articular deformity. J Arthroplasty. 2009;24(8):1164-9.

16. Devers BN, Conditt MA, Jamieson ML, Driscoll MD, Noble PC, Parsley BS. Does greater knee flexion increase patient function and satisfaction after total knee arthroplasty? J Arthroplasty. 2011;26(2):178-86.

17. Ritter MA, Lutgring JD, Davis KE, Berend ME. The effect of postoperative range of motion on functional activities after posterior cruciate-retaining total knee arthroplasty. J Bone Joint Surg Am. 2008;90(4):777-84.

18. Meneghini RM, Pierson JL, Bagsby D, Ziemba-Davis M, Berend ME, Ritter MA. Is there a functional benefit to obtaining high flexion after total knee arthroplasty? J Arthroplasty. 2007;22(6 Suppl 2):43-6.

19. Matsumoto T, Tsumura N, Kurosaka M, Muratsu H, Yoshiya S, Kuroda R. Clinical values in computer-assisted total knee arthroplasty. Orthopedics. 2006;29(12): 1115-20.

20. Noble PC, Scuderi GR, Brekke AC, Sikorskii A, Benjamin JB, Lonner JH et al. Development of a new Knee Society scoring system. Clin Orthop Relat Res. 2012;470(1):20-32. 